\section{International Sports Federation's fight to protect the clean athlete: are we doing enough in the fight against doping?}

\author{
Margo Mountjoy, ${ }^{1,2}$ Stuart Miller, ${ }^{3}$ Matteo Vallini, ${ }^{4}$ Jeremy Foster, ${ }^{5}$ \\ James Carr ${ }^{5}$
}

\section{ANTIDOPING CLIMATE}

The antidoping landscape has seen significant changes recently. Doping in sport, and integrity in a wider sense, have been the subject of greater scrutiny than ever before. The WADA and other antidoping organisations (ADOs) have been criticised for being subject to conflicts of interest, whether real or perceived. Conflicts of interest indicate failure of governance. That is, the governance structures within such ADOs are insufficient to give stakeholders comfort that those organisations are free from undue influence. One way in which these criticisms could be addressed is by implementing and enforcing governance principles that would see various components of an antidoping programme, including sample collection, analysis, results management and therapeutic use exemptions (TUEs), independent from that ADO's political arm-Russia, for example.

Antidoping in Russia is a case in point. The suspensions by WADA of the Russian National Anti-Doping Organisation and the Moscow antidoping laboratory and the allegations related to activities at the (then-WADA-accredited) antidoping laboratory in Sochi 2014, combined with the sanctioning of athletes following retests of samples from the 2008 and 2012 Olympic games, have led to the view that the current antidoping system is not 'fit for purpose' today, and certainly

'Department of Family Medicine, Michael G DeGroote School of Medicine, McMaster University, Hamilton, Ontario, Canada

${ }^{2}$ IOC Medical Commission-Games Group, Lausanne, Switzerland

${ }^{3}$ International Tennis Federation, London, United Kingdom

${ }^{4}$ Doping-Free Sport Unit, SportAccord, Lausanne, Switzerland

${ }^{5}$ The Association of Summer Olympic international Federations (ASOIF), Lausanne, Switzerland

Correspondence to Dr Margo Mountjoy, Michael G. DeGroote School of Medicine, McMaster University Waterloo Regional Campus, 10-B Victoria Street South, Kitchener, Ontario, Canada; mmsportdoc@mcmaster.ca
Box 1 Anti-doping topics included

in the Association of Summer

Olympic International Federations

anti-doping survey of summer

International Federations

- Incorporation of intelligence in antidoping practices

- Determination of the IF registered testing pool

- IF test distribution plan: in and out of competition testing strategies

- Athlete biological passport

- Therapeutic use exemptions and the utilisation of the online Anti-Doping Administration and Management System

- Results management

- Hearings and sanctions

Antidoping programme expenditures

not appropriate to face the challenges of the future. Among others, the IOC published a declaration in October 2016, calling for a 'more robust, more efficient, more transparent and more harmonised WADA anti-doping system... (including) better governance..., increased security... and increased financing. ${ }^{1}$ It is incumbent on all stakeholders, including WADA, public authorities (governments) and sport, including the IOC and International (Sporting) Federations (IFs) to share responsibility in facing those challenges.

\section{ACTIVITIES OF THE IFS IN THE FIGHT AGAINST DOPING}

The Summer Olympic IFs, under the leadership of the Association of Summer Olympic International Federations (ASOIF), commissioned an antidoping study under the guidance of the ASOIF Medical and Scientific Consultative Group (see online supplementary appendix 1). The objectives were to:
- Establish the antidoping processes that individual IFs implement within their respective sports;

- Quantify the financial resources devoted to the IFs' antidoping efforts in 2015;

- Compare these resources with those reported in 2010 and

- Identify best practices from IFs' experiences on how to better protect the clean athlete.

An online survey of all Summer Olympic IFs (see online supplementary appendix 1) was conducted in March and April 2016, which evaluated the antidoping practices and expenditures in the 2015 calendar year. Box 1 summarises the antidoping topics included.

The response rate to the survey was $100 \%$, therefore the results are considered to be a valid representation of the current state of antidoping practices of the IFs for the period surveyed. All 28 IFs were WADA-Code compliant in 2015 and had active antidoping programmes. In 2015, the IFs conducted a total of 32889 tests (of which 22125 were collected in-competition and 10764 out-of-competition), which resulted in 219 'positive tests' or Anti-Doping Rule Violations (ADRVs)-a $38 \%$ increase compared with 2009 (159). The majority of IFs (79\%) use the athlete biological passport (ABP) as part of their antidoping programme; however, there was a significant variation in the number of ABP samples collected across IFs (1-1998).

In accordance with the requirements of the 2015 WADA Code requirement, 75\% of IFs engaged in intelligence gathering in 2015 and $93 \%$ of IFs used intelligence for the purpose of informing test distribution programmes. The average cost to the IF to process a TUE application increased significantly between 2009 and 2015 (from US\$74 to US\$342). Over the same period, the total number of TUEs were reduced by $80 \%$, mainly due to the removal by WADA of the requirement for the use of all beta-2 agonists (which are used to treat asthma) to require a TUE. Almost all IFs (93\%) use ADAMS for TUE management and the majority (64\%) process TUE applications within 7 days. There is greater recognition of TUEs between IFs and National ADOs since 2009.

\section{IF EXPENDITURE ON ANTIDOPING Total antidoping costs}

Total antidoping expenditure by IFs in 2015 was US $\$ 27.7 \mathrm{M}$, which represents an $18 \%$ increase over 2009 . The summer IFs spend roughly the same amount per 
year as WADA (approximately US\$29M USD).

\section{Uneven IF expenditures}

The total expenditure described above was not evenly distributed across IFs. The six highest spending IFs account for $80 \%$ of all IF antidoping expenditure; each spending more than US\$1M on antidoping in 2015. By contrast, the 17 lowest spending IFs account for $11 \%$ of the total expenditure. All 17 spent less than US\$300 000 USD in 2015. Even so, the lowest spending 17 IFs spent $82 \%$ more on antidoping than in 2009.

\section{Human resources}

Expenditure on human resources in antidoping by IFs increased by $128 \%$ since 2009, from US\$2.1 to US\$4.8 million. This substantial change likely reflects the increase in human resource costs necessary to implement the more complex requirements of the 2015 WADA Code.

\section{Costs}

Testing is the most expensive component of IF antidoping processes and comprised an average of $70 \%$ of the total antidoping budget. In comparison with 2009, the cost per test has decreased significantly (from US\$825 to US\$387 per test). Although reasons for the cost savings were not determined in the survey, the cause is likely multifactorial: more strategic test distribution planning, a reduction in analysis costs due to targeted testing (partial menu analyses) and economies of scale through use of external antidoping service providers.

\section{Antidoping education}

While $100 \%$ of IFs have antidoping education programmes, less than half (48\%) stated they had measure the effectiveness of those programmes. Despite the explicit requirement for antidoping education in the 2015 WADA Code, IFs are spending proportionately less on education than in 2009 (4.1\% of total budget in 2009 vs $2.9 \%$ in 2015).

Code implementation logistical changes To meet the requirements in the 2015 WADA Code, IFs are seeking greater assistance with their antidoping programmes by outsourcing $70 \%$ of antidoping tasks to external sources in 2015 than in 2009 when antidoping costs were evenly split between internal and external costs. This may be due to the development and availability of specialised antidoping service providers (eg, sample collection agencies).

\section{The bottom line}

In comparison to 2009, IFs have realised significant cost savings in the implementation of their antidoping programmes:

- ADRV costs have decreased by 30\%

- Adverse analytical findings costs have decreased by $61 \%$

- Atypical findings costs have decreased by $10 \%$

- Results management costs have decreased by $74 \%$

Despite these cost savings, IFs are spending more on their antidoping budgets, most of which is spent on testing and an increase in human resources.

\section{Conclusions}

Are the IFs doing enough to protect the clean athlete? All 28 summer IFs are WADA Code compliant and have made significant changes to their antidoping programmes over the last 6 years, particularly in regards to the use of intelligence-led testing and the ABP. The IFs are spending more money on antidoping than in 2009, and have realised significant cost savings. The end result is a greater number of ADRV than in 2009.

Is this good enough? The tumultuous year of antidoping drama in 2016 indicated that there is no room for complacency. This ASOIF survey shows that some IFs could do more. As the McLaren Independent Report ${ }^{2}$ shows, the antidoping system has come up short in ensuring a level playing field. Changes to antidoping systems are required to better protect the clean athlete-including improved governance, transparency, efficiency and increased independence.

Acknowledgements The authors sincerely thank the 28 International Federations for their cooperation and contribution to the ASOIF antidoping survey 2016. Thank you also to the leadership of ASOIF for the support of the International Federation antidoping survey and IF Forum: 'The power of sport to drive athlete health'. The authors graciously acknowledge the teamwork of the ASOIF Medical and Scientific Group in the project.

Contributors Scientific contributions of each author: MM: First author, substantial contributions to conception and design, coordination of paper, drafting and revising the manuscript and approval of final version to be published. SM, MV, JF, JC: Substantial contributions to conception and design, data analysis, revising the manuscript and approval of final version to be published.

Competing interests None declared.

Provenance and peer review Not commissioned; externally peer reviewed.

Data sharing statement There are no unpublished data from the survey available.

\section{(6) OPEN ACCESS}

Open Access This is an Open Access article distributed in accordance with the Creative Commons Attribution Non Commercial (CC BY-NC 4.0) license, which permits others to distribute, remix, adapt, build upon this work non-commercially, and license their derivative works on different terms, provided the original work is properly cited and the use is non-commercial. See: http:// creativecommons.org/licenses/by-nc/4.0/

(c) Article author(s) (or their employer(s) unless otherwise stated in the text of the article) 2017. All rights reserved. No commercial use is permitted unless otherwise expressly granted.

- Additional material is published online only. To view, please visit the journal online (http://dx.doi.org/ 10.1136/bjsports-2017-097870).

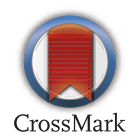

To cite Mountjoy M, Miller S, Vallini M, et al. Br J Sports Med 2017;51:1241-1242.

Accepted 28 May 2017

Br J Sports Med 2017;51:1241-1242.

doi:10.1136/bjsports-2017-097870

\section{REFERENCES}

1 Declaration of the 5th Olympic Summit, Lausanne, Switzerland. 2016 https://stillmed.olympic.org/media/ Document\%20Library/OlympicOrg/News/2016/10/ 2016-10-08-Declaration-Olympic-Summit.pdf (accessed 8 Oct 2016)

2 McLaren R. McLaren independent investigation report - part I and part II. https://www.wada-ama.org/en/ resources/doping-control-process/mclaren-independentinvestigation-report-part-ii (accessed 8 Jan 2017). 